https://www.journal-imab-bg.org

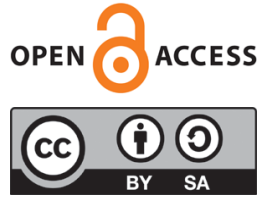

Original article

\title{
CORRELATION BETWEEN SLEEP APNEA AND METHADONE THERAPY
}

\author{
Christiana Madjova ${ }^{1}$, Simeon Chokanov$^{1}$, Mario Milkov ${ }^{2}$ \\ 1) Department of Conservative Dentistry and Oral Pathology, Faculty of Den- \\ tal Medicine, Medical University - Varna \\ 2) Department of Dental Materials Science, and Propaedeutics of Prosthetic \\ Dental Medicine, Faculty of Dental Medicine, Medical University - Varna, Bul- \\ garia.
}

\section{SUMMARY}

Introduction: Methadone therapy is the mainstay of treatment of addict patients. The most common side effects are: dizziness, drowsiness, vomiting, sweating, dry mouth and constipation. The more serious complications that can be observed are: sleep apnea, àbnormal heart rhythms, respiratory problems, euphoria, disorientation, anxiety, seizures and more.

Purpose: The purpose of this study is to determine the correlation between methadone maintenance treatment and sleep apnea in addict patients.

Materials and methods: The subject of the study are 81 methadone-treated drug-dependent patients, mean age 39 $\pm 9,07$ years.

Results: The answers we received: $79 \%$ (64) of drug addicts have problems with sleep; $30.9 \%$ of them (25) reported having insomnia; $44.4 \%$ (36) experience morning fatigue; $56.8 \%$ (46) of the respondents said they were drowsy during the day and $63 \%$ of the respondents reported a change in mood; $21 \%$ (17) had a short sleep, and 26\% (21)reported snoring and 18 of them have loud bothering snoring; $68 \%$ answered that they don't have problems with falling asleep and only $21 \%$ don't wake up frequently in the evening. In $83.9 \%$ nobody noticed cessation of breathing during sleep. $73.8 \%$ never nodded off or fallen asleep while driving a vehicle. $16.1 \%$ have been treated for high blood preasure, and only $2.5 \%$ have obesity.

Conclusions: Our survey found that there is a correlation between methadone therapy and sleep of patients. The key to improving the condition and reducing the risk of central sleep apnea is the monitoring of patients, as well as a combination of different types of treatment.

Keywords: Methadone, Opiate dependence, Drug addicts, Sleep apnea, Central sleep apnea, Sleep disorders,

\section{INTRODUCTION}

Methadone is an opioid used to treat chronic pain as well as supportive therapy in opioid-dependent patients. Its most common side effects are: dizziness, drowsiness, vomiting, sweating, dry mouth and constipation. [1,2]. The more serious complications that can be observed are: sleep apnea, àbnormal heart rhythms, respiratory problems, euphoria, disorientation, anxiety, seizures and more [2, 3, 4].
Addiction is a brain disorder that creates mental and/ or physical dependence. It tortures millions of people around the world, which costs society a great deal in terms of medical and social problems, and immeasurable suffering for loved ones and for themselves [5]. Addiction is most commonly observed for opioid drugs. The patients we examined were addicted to heroin. There are different modes of its administration: from smoking, sniffing to oral and intravenous heroin intake [5]. Drug addicts have the highest psychoactive effect through intravenous administration, which is also the most dangerous.

Drugs are chemicals that affect a person's physical, mental and social functions by changing them in various aspects. The use and abuse of narcotic substances is common and increasing in recent years. This is a socially significant problem worldwide [6].

Methadone therapy is the mainstay of treatment of addict patients. Methadone is a synthetic opiate has a longer action than heroin and acts on the same opioid receptors. Its euphoric effect is less pronounced. Patients take it orally to treat their addiction. If injected intravenously, it will give a heroin-like intoxication. It is essential that methadone therapy is monitored by a doctor because methadone is also addictive and can have side effects. Methadone intoxication and abstinence are more powerful than heroin.

The purpose of this study is to determine the correlation between methaone maintenance treatment and sleep apnea in addict patients.

\section{MATERIALS AND METHODS}

Our survey was conducted among 81 drug addicted patients treated with methadone, 58 men $(72 \%)$ and 23 women (28\%). Prior to the survey, they signed informed consent and completed an anonymous survey. Most of them were treated at University Hospital "St. Marina" - Varna in the Department of Psychiatry and Medical Psychology and were monitored outpatientin the Diagnostic Consultative Center "St. Marina"- Varna, where we conducted the survey.

Patients met several including criteria: to be on methadone therapy for at least 2 months, to be addicted to opioid drugs, to complete informed consent.

All participants filled an anonymous survey in order for their sleep problems to be clarified in details. The study 
consisted of 14questions for sleep assessment. The issues of the survey refer to problems with sleep, mood swings, snoring and quality of sleep.We used the scientific literature to compare our data from a polysomnographic study for sleep apnea in methadone therapy.

\section{RESULTS}

The 81 patients we examined were $39 \pm 9,07$ years of age (mean $\pm \mathrm{SD})$. The proportion between men and women was unequal. Themen are twice as many as women (58 versus 23). Their distribution as a percentage is given in Figure 1.

All of them are drug addicts, treated at the University Hospital "Saint Marina" and monitored at Diagnostic Consultative Center "Saint Marina"- Varna, where we conducted the polysomnographic study and the survey.

Fig. 1. Percentage of examined patients

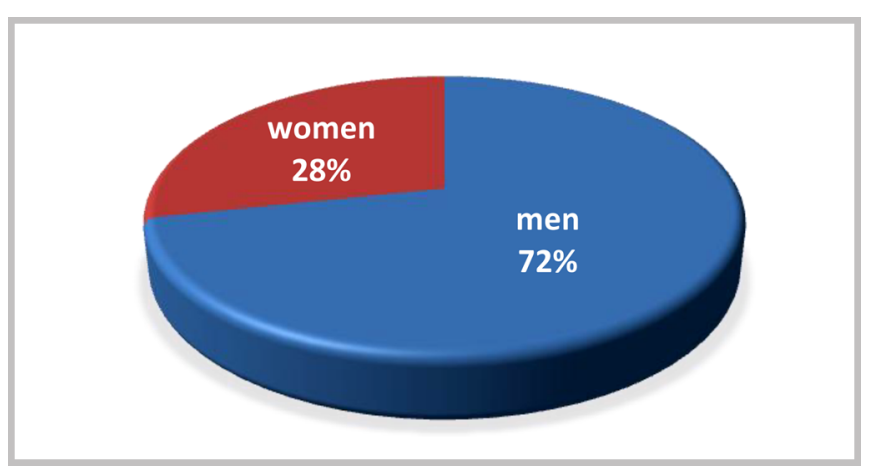

We prepared a special questionnaire for patients. After they filled it, we summarized the received answers by calculating the percentage of answers with "Yes" or "No", respectively, and the results are shown in Figures 2 to 11, 14 and 15. Two of the questions had multiple choice, they are shown in Figures 12 and 13.

The first question was about sleeping problems whether or not patients had them. We found that $79 \%$ said they had (fig.2). Each patient reported a different sleep problem.

On the following questions, the received answers are shown as a percentage:

- "Do you suffer from insomnia?" 25 (30,9\%) responded positively

• "Do you have morning fatigue?" - 44.4\% (36) said they experience morning fatigue

- "Do you feel sleepy during the day?" 56,8\% (46) answered negatively day"

- $63 \%$ of patients reported "mood swings during the

- To the questions "Is your dream short?" and "Do you snore?" patients who answered "yes" were respectively $21 \%$ (17) and 26\% (21)

- From patients who answered yes on previous question (21pts), 18 answered that their snoring bothered other people

- $26(32 \%)$ patients had difficulty falling asleep.

- $21 \%$ (17) of the respondents do not wake up often in the evening
- "Has anyone noticed that you quit breathing during your sleep?"'- Nearly every day (0 pts); 3-4 times a week (2 pts, 2.5\%); 1-2 times a week(3 pts, 3.7\%); 1-2 times a month( 8 pts, $9.9 \%)$; Never or nearly never(68 pts, $83.9 \%$ )

- On the question "Have you ever nodded off or fallen asleep while driving a vehicle?"- 1 patient (1.2\%) answered "nearly every day"; 3 patients $(3.7 \%)$ - 3-4 times a week; 5 patients $(6.2 \%)$ - 1-2 times a week; 1-2 times a month (13 pts, $16.1 \%)$; and "never or nearly never" -59 pts $(72.8 \%)$

- Do you have or are you being treated for high blood pressure? -13 patients $(16.1 \%)$ have positively

- BMI $\geq 35 \mathrm{~kg} / \mathrm{m}^{2}$ ? - only 2 patients $(2.5 \%)$ answered

Fig. 2. The share of pts with the sleep problem

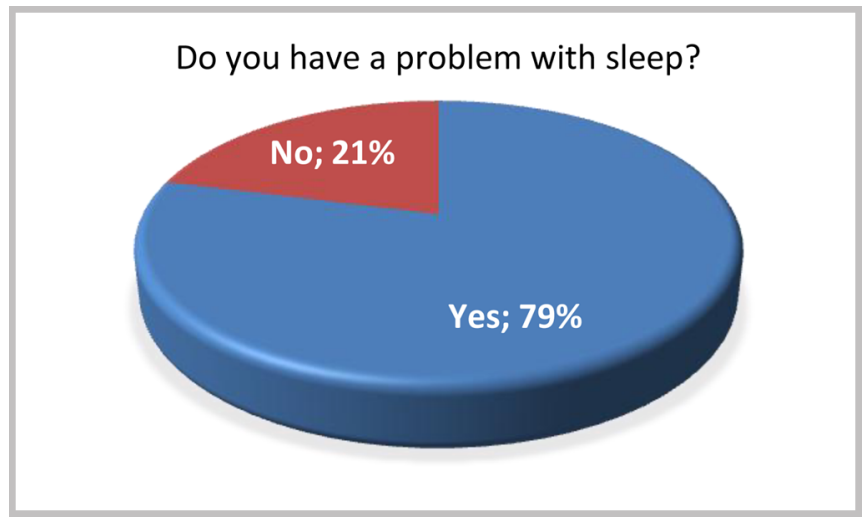

Fig. 3. The share of pts with insomnia

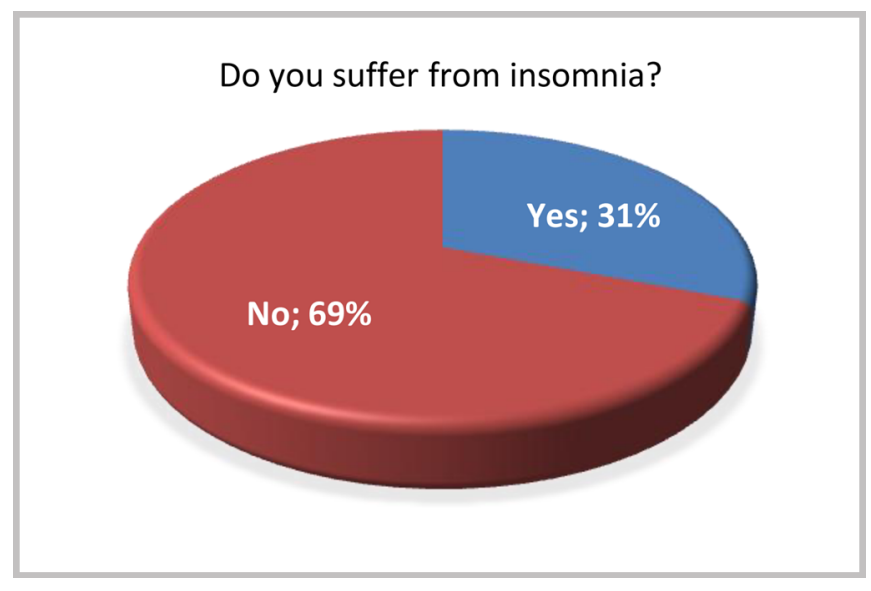

Fig. 4. The share of pts with morning fatigue

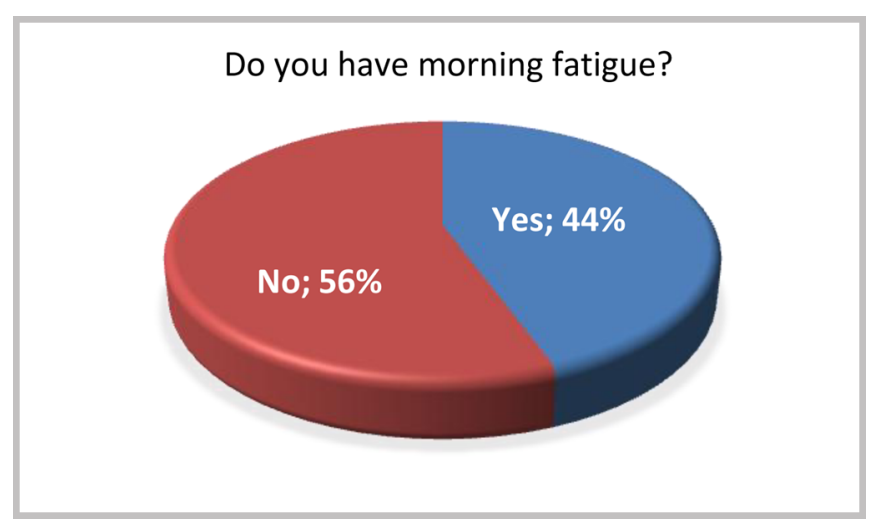


Fig. 5. The share of pts feeling sleepy during the day

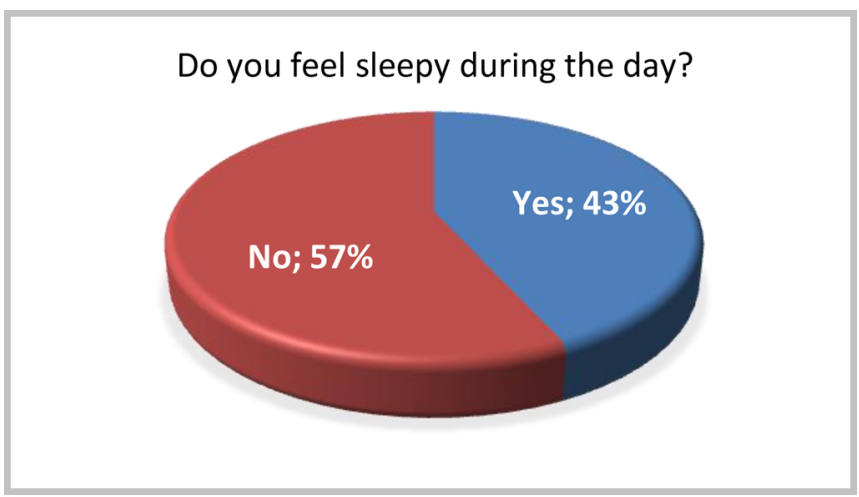

Fig. 6. The share of pts with mood swing

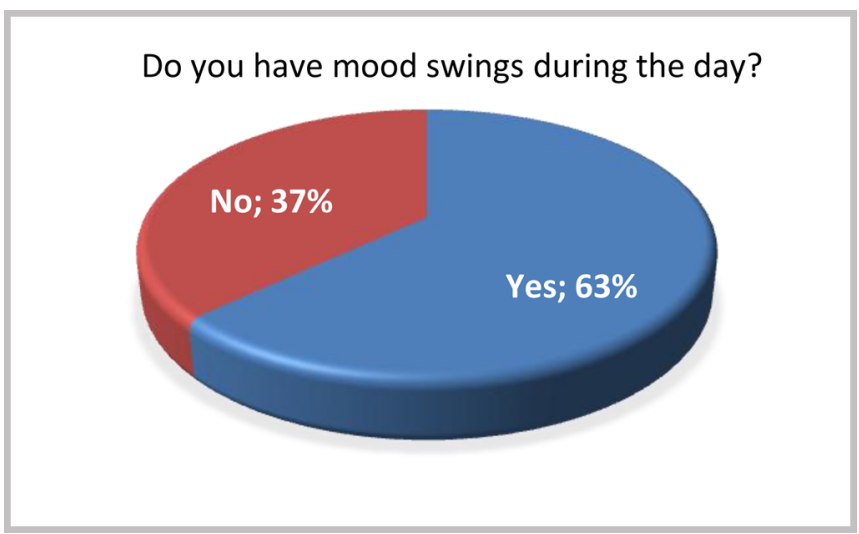

Fig. 7. The share of pts with a short dream

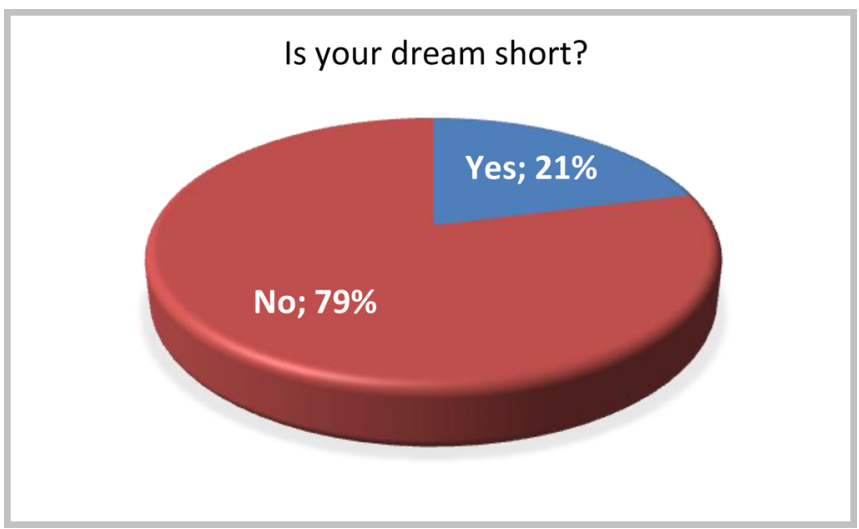

Fig. 8. The share of pts with snoring

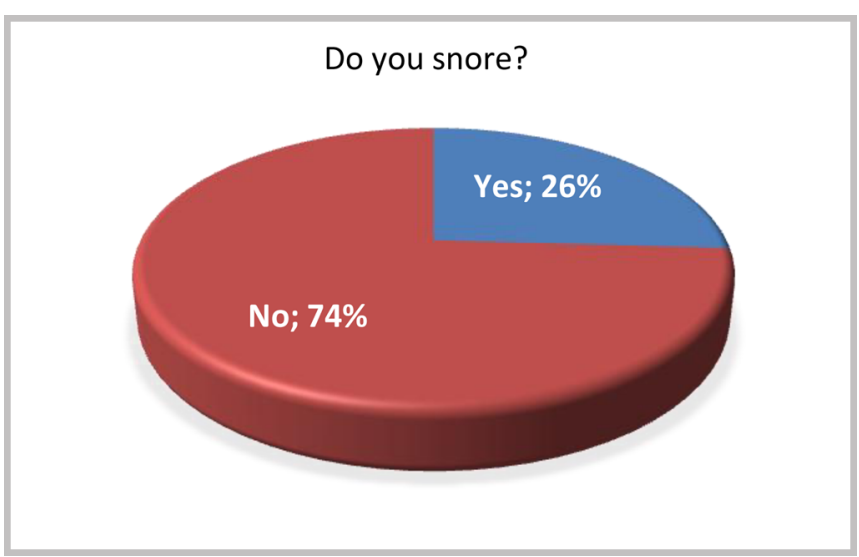

Fig. 9. The share of pts whossnoring bother others

Has your snoring ever bothered other people?

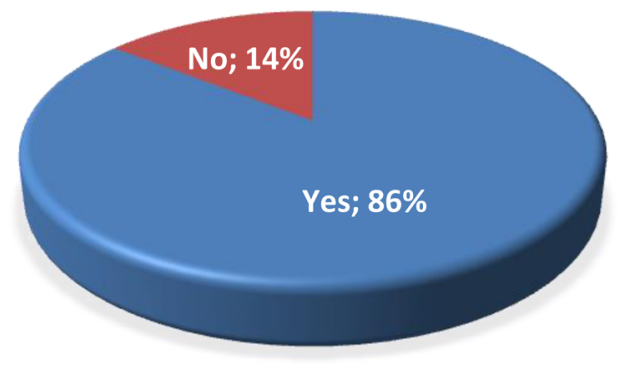

Fig. 10. The share of pts who hard falling asleep

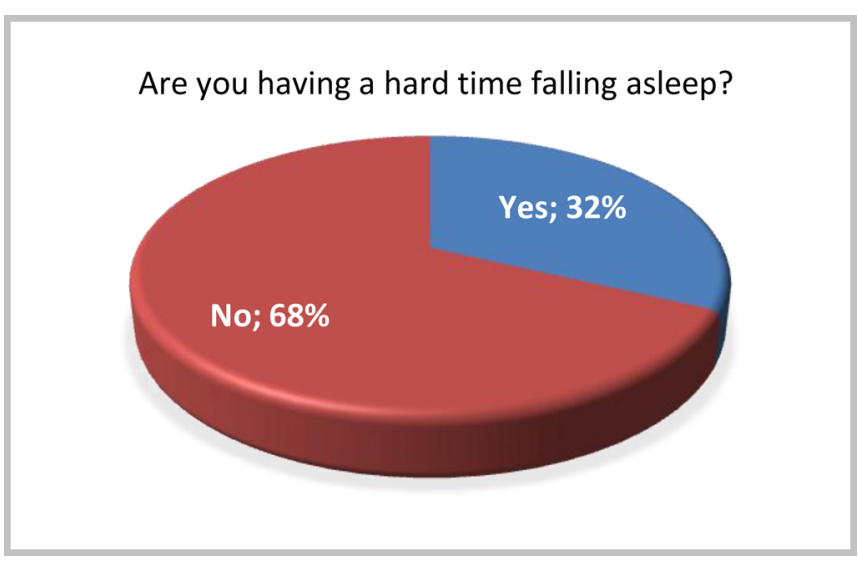

Fig. 11. The share of pts who often wake up

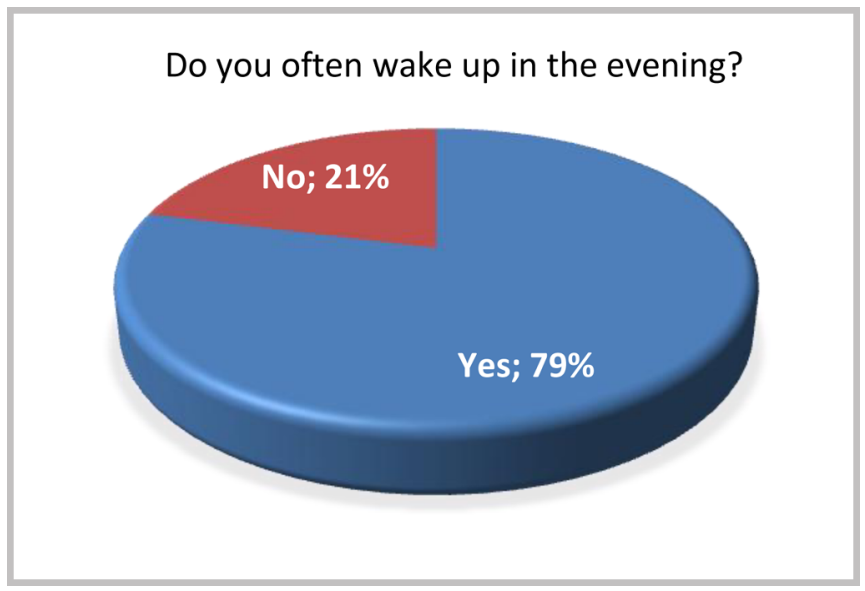


Fig. 12. The share of pts whos partner noticed cessation of breathing

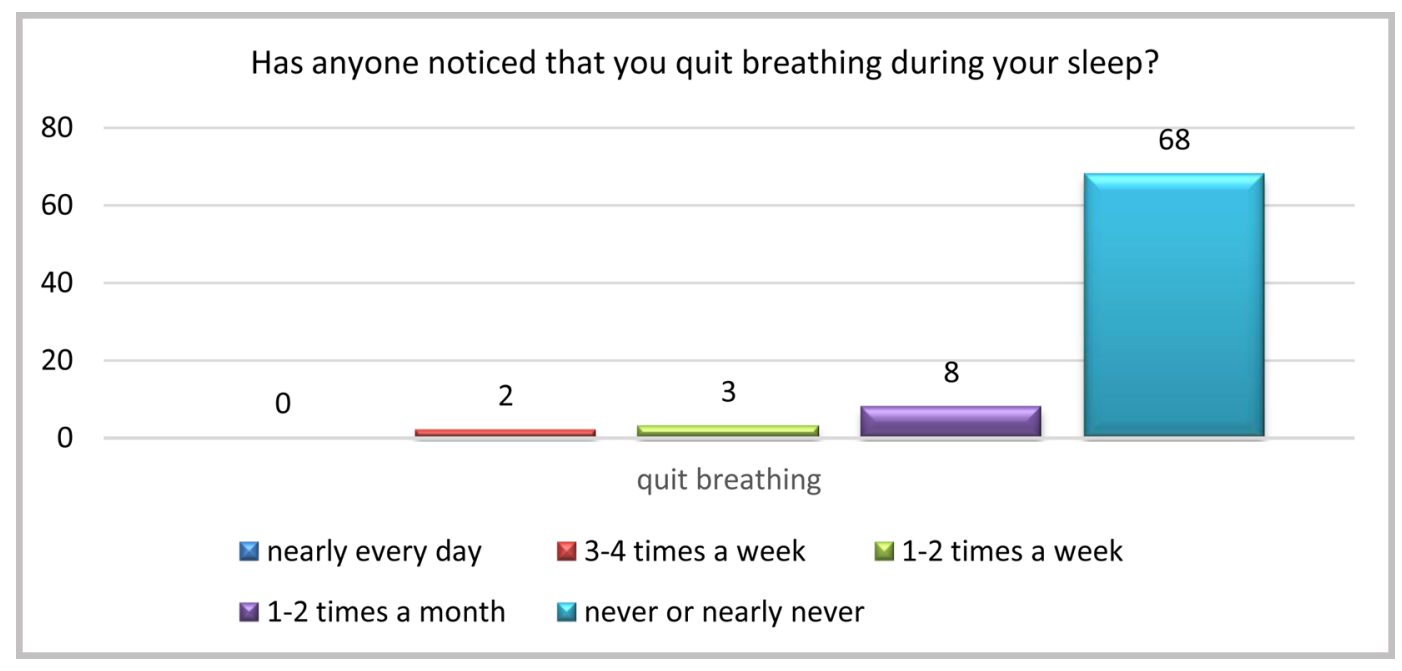

Fig. 13. The share of pts whoever nodded off or fallen asleep while driving a vehicle

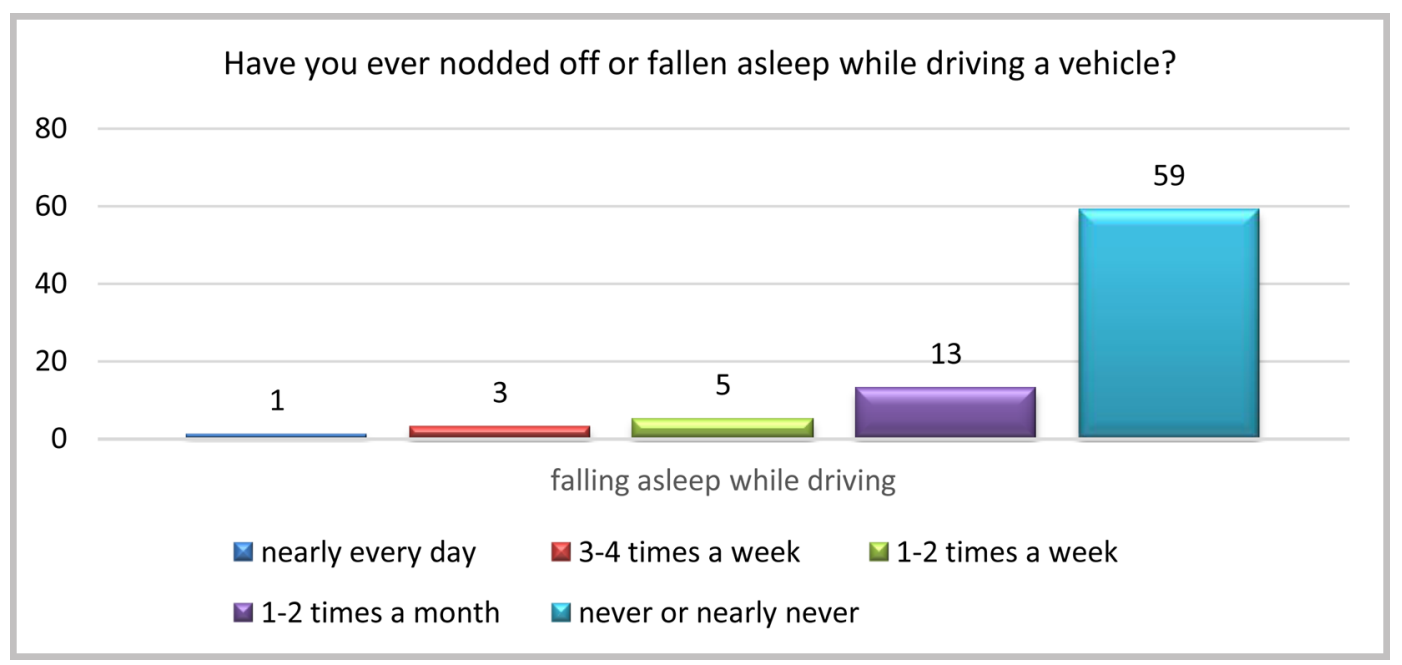

Fig. 14. The share of pts who are /have been treated for high blood pressure

Do you have or are you being treated for high blood pressure?

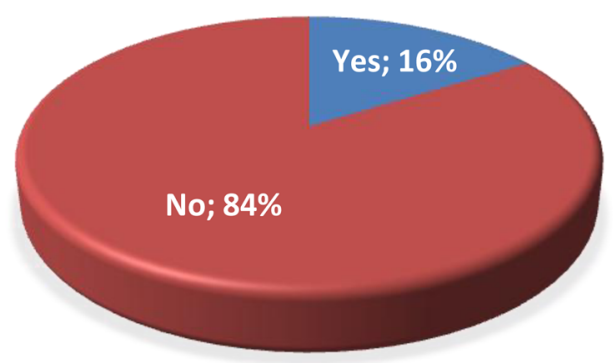

Fig. 15. The share of pts with $B M I \geq 35 \mathrm{~kg} / \mathrm{m} 2$

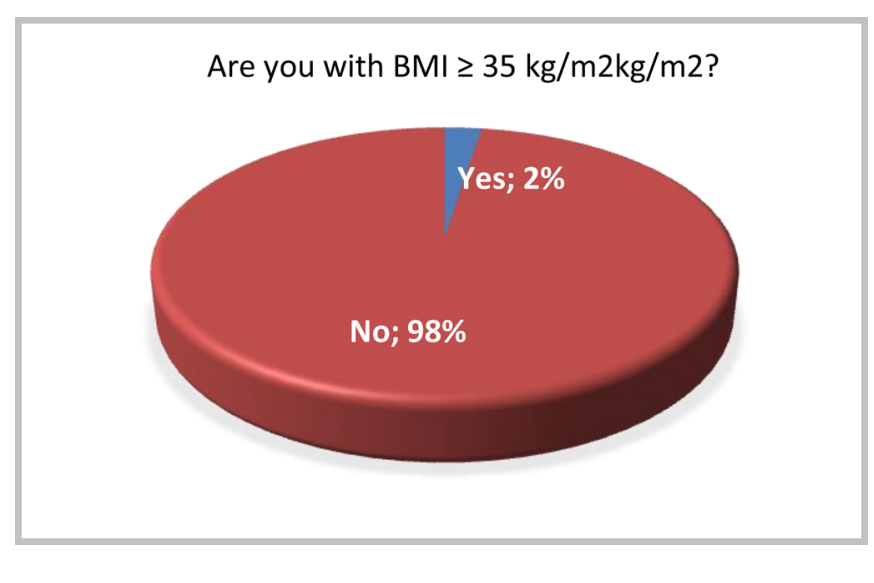

\section{DISCUSSION}

The relationship between drugs use and sleep is twoway. On the one hand, opioid use causes sleep disorders, and on the other, sleep problems affect recurrent opiate abuse [7].

Central sleep apnea (CSA) is characterized by a lack of airflow for $\geq 10$ seconds with no effort of breathing, and 
an apnea-hypopnea index (AHI)of more than 5 per hour is considered significant [8].

For the diagnosis of central sleep apnea in opioiddependent patients, there are 3 clinical symptoms that may be present both individually and together: 1) the respiratory pattern - ataxia or irregularly; 2) interruption of breathing - apnea or hypopnea 3) gas exchange - hypoxia and hypercapnia. Central apnea may have different morphology: irregular intervals with ataxic respiration or periodic with cluster respiration [8].

Polysomnographic examination is the gold standard for diagnosing OSA, but it is a time-consuming and costly procedure. To address this problem, many studies use developed screening questionnaires to help identify patients with OSA.The survey method is a proven useful, simple and alternative approach used to diagnose sleep apnea by asking patients to report their symptoms $[9,10]$. Our questionnaire is a self-administered screening tool, which combines questions about the risk factors for sleep apnea. In this way, the risk can be determined.

Breathing disorders during sleep (sleep disordered breathing) in patients using opiates are extremely high. According to the study of Correa D et al., they range from $42 \%$ to $85 \%$, and the incidence of central sleep apnea is many times higher than in the general population (24\%) [8].

After taking opioids, breathing becomes shallow and irregular, leading to hypercapnia and hypoxia. The specific one observed by Randerath WJ and George S (2012) in opioid-induced sleep apnea patients is daytime drowsiness, dizziness, and impaired concentration [11].

For the most accurate diagnosis of central sleep apnea, a polysomnographic study should be used as well as a multidisciplinary team. Two abnormal breathing patterns are observed in diagnosed patients - reduced effort to inhale during an obstructive event and longer than expected respiration pauses [14]. In a polysomnographic study done by Sharkey, K, and a team of 71 methadone patients, $42.2 \%$ of participants had at least one form of SDB [15]. Correa D. and Farney R. observed central sleep apnea (CSA) in a study of patients receiving methadone therapy [8]. With this type of sleep apnea, patients stop breathing or breathing is very low, and they cannot supply oxygen. It presents a more serious treatment challenge.

The major risk of methadone use is death from respiratory depression, especially when initiating therapy or changing doses [12]. Many studies have shown that methadone therapy leads to an increase in the incidence of sleep apnea symptoms, and the quality of sleep in these patients is very poor. This reflects on the quality of life of patients [13].

The data we obtained showed that addicts receiving methadone patients have trouble sleeping. The explanation of this in the literature is that unlike obstructive sleep apnea, in which the muscles of the throat are relaxed, in central sleep apnea (more common in opioids use), the brain does not send the correct signals to the muscles that control breathing.

We found that $79 \%$ of patients reported sleep problems. Different symptoms vary within various limits. Patients stop breathing for a certain period of time, have trou- ble with sleep and wake up. These short, breath-taking awakenings are typical of central sleep apnea. Mood changes are also one of the symptoms of apnea, but they overlap with patients' mental state, and addiction treatment has many effects on them.

We observed other typical symptoms we observed in our patients have increased daytime sleepiness in $56.8 \%$ and morning fatigue in $44.4 \%$.Many of these patients have insomnia $(30,9 \%)$. A smaller percentage of those surveyed were found to have short sleep and snore.

What the partner of the respondents thinks is extremely important for conducting this survey. Some of the questions focused on what others were saying about the sleeper. In $83.9 \%$ of drug addicts, their partners did not notice the symptom of sleep apnea - cessation of breathing.

It is crucial that $27.2 \%$ percentage of patients nodded off or fell asleep while driving. This may be due to both fatigues from sleep apnea and opiates taken by the subjects. It is very difficult to distinguish the cause of this problem.

Other risk factors for sleep apnea are obesity and high blood pressure. In this study, we did not find it to affect drug addicts. A very small percentage of those surveyed had $\mathrm{BMI} \geq 35$.

How to manage sleep apnea in methadone treated addicted?

Guilleminault C. (2010) showed the most accurate diagnosis of central sleep apnea is a combination of polysomnographic study and discussions with a multidisciplinary team. He has observed 2 abnormal breathing patterns in the diagnosed patients - reduced effort to inhale during an obstructive event and longer than expected respiration pauses [14].

Treating patients with sleep apnea as a result of opioids is extremely challenging. There are different study and opinions. According to Correa D. and Farney R. (2015), constant positive pressure apparatus is most commonly used for treatment, and different types of oxygen devices are used. Some patients may require a reduction in the opiate dose or the choice of another drug with less methadone toxicity (such as buprenorphine), as well as drug treatment with acetazolamide, theophylline and carbon dioxide [8].

Troitino A. et al. (2014) made a study in patients with sleep disorders, and his conclusion is that patients with central sleep apnea due to opiates are not significantly affected by CPAP (Continuous positive airway pressure therapy) treatment. Only $24 \%$ of addicted showed improvement compared with the control group with idiopathic central sleep apnea (38\%) [16].

Guilleminault and the team also observe the same, but they report differences in obese patients and those with lower BMI. In their view, those with lower body weight have a different breathing pattern, which respond well to CPAP therapy [14].

Oxygen therapy corrects hypoxemia but does not affect patients' ataxic breathing. Patients may experience potentiation of hypoventilation or prolongation of central apnea/hypopnea. But oxygen therapy rarely causes respiratory depression, as opioids stabilize respiration if the 
arousal threshold is low and the respiratory controller gain is high, associated with pain. Oxygen is added in addition to CPAP treatment for optimal treatment [8].

\section{CONCLUSION:}

We found in our study that there is a correlation between methadone therapy and the sleep of patients. De- spite the high prevalence of sleep problems in drug addicts, this therapy is necessary and should be closely monitored by their psychiatrists. The key to improving the condition and reducing the risk of central sleep apnea is in monitoring patients, as well as a combination of different types of treatment.

\section{REFERENCES:}

1. Martin WR, Jasinski DR, Maintenance Treatment Volunteers and Haertzen CA, Kay DC, Jones BE, Opium-dependent Patients. Addict Mansky PA, et al. Methadone-a Health. 2016 Apr;8(2):84-89. [PubMed] reevaluation. Arch Gen Psychiatry. 1973 Feb;28(2):286-95. [PubMed]

2. Nicholson AB, Watson GR, Derry $\mathrm{S}$, Wiffen PJ. Methadone for cancer pain. Cochrane Database Syst Rev. 2017 Feb 8;2(2):CD003971. [PubMed]

3. John J, Amley X, Bombino G, Gitelis C, Topi B, Hollander G, et al. Torsade de Pointes due to Methadone Use in a Patient with HIV and Hepatitis C Coinfection. Cardiol Res Pract. 2010 Dec 30;2010:524764. [PubMed]

4. Sinha S. Methadone. Drugs.com. Nov. 2019 [nternet]

5. Koob G, Arends M, Le Moal M. Drugs, Addiction, and the Brain. 1st Edition. Academic Press, Elsevier. 2014. Chapter 1: vii. [Internet]

6. Fudin HR, Babin JL, Hong JT, Ku J, May AL, Wisner A, et al. Drugs of Abuse. Side Effects of Drugs Annual. Volume 40, 2018. Chapter 4. pp.29-89 [Crossref]

7. Khazaie H, Najafi F, Ghadami MR, AzamiA, Nasouri M, Tahmasian $\mathrm{M}$, et al. Sleep Disorders in Methadone
Breathing, and the Endocrine System. In: Handbook of Methadone Prescribing and Buprenorphine Therapy. Editors Cruciani R, Knotkova H. Springer, New York, NY. 2013. pp.39-49. [Crossref]

13. Charpentier A, Bisac S, Poirot I, Vignau J, Cottencin O. Sleep quality and apnea in stable methadone maintenance treatment. Subst Use Misuse. $2010 \mathrm{Jul} ; 45(9): 1431-4$. [PubMed]

14. Guilleminault C, Cao M, Yue HJ, Chawla P. Obstructive sleep apnea and chronic opioid use. Lung. 2010 Dec;188(6):459-68. [PubMed]

15. Sharkey KM, Kurth ME, Anderson BJ, Corso RP, Millman RP, Stein MD. Obstructive sleep apnea is more common than central sleep apnea in methadone maintenance patients with subjective sleep complaints. Drug and Alcohol Dependence, 2010; 108(1-2), 77-83

16. Troitino A, Labedi N, Kufel T, El-Solh AA. Positive airway pressure therapy in patients with opioid-related central sleep apnea. Sleep Breath. 2014 May;18(2):367-73. [PubMed]

Please cite this article as: Madjova C, Chokanov S, Milkov M. Correlation between sleep apnea and methadone therapy. J of IMAB. 2021 Apr-Jun;27(2):3817-3822. DOI: https://doi.org/10.5272/jimab.2021272.3817

\author{
Address for correspondence: \\ Christiana Madjova \\ Department of Conservative Dentistry and oral pathology, Faculty of Dental \\ Medicine, Medical University - Varna. \\ 84, TzarOsvoboditel Blvd., 9000 Varna, Bulgaria \\ E-mail: christiana.madjova@gmail.com,
}

